\title{
Association Between Coronary Artery Atherosclerosis and the Intima-Media Thickness of the Common Carotid Artery Measured on Ultrasonography
}

\author{
Eduardo Maffini da Rosa, Caroline Kramer, Iran Castro \\ Porto Alegre, RS - Brazil
}

\begin{abstract}
Objective - To assess whether the intima-media thickness of the common carotid artery of patients with coronary artery disease is greater than that of individuals without that disease.
\end{abstract}

Methods - Case-control prospective study of prevalence assessing the thickness of the intima and media layers of 29 patients with coronary artery disease and 29 individuals without that disease by using ultrasonography of the carotid arteries. Diabetic patients and those with peripheral artery and cerebral vasculopathies were excluded from the study.

Results - The mean age was $51 \pm 7.5$ years. Fifty-five per cent of the patients were males. Acute myocardial infarction was present in $62 \%$; cardiac catheterization in $72 \%$; saphenous bypass in $5 \%$; and coronary angioplasty in $24 \%$. The intima-media thickness of the common carotid artery in case patients and in control patients was, respectively, $0.81 \pm 0.25 \mathrm{~mm}$ and $0.62 \pm 0.18 \mathrm{~mm}(P=0.001)$.

Conclusion-Intima-media thickness of the common carotid artery was significantly greater in patients with coronary artery disease.

Key words: coronary artery disease, intima-media thickness, common carotid artery

Instituto de Cardiologia do Rio Grande do Sul/Fundação Universitária de Cardiologia.

Mailing address: Iran Castro - Unidade de Pesquisa do IC/FUC - Av. Princesa Isabel, 395 - 90620-001 - Porto Alegre, RS, Brazil

E-mail: pesquisa@cardnet.tche.br

English version by Stela Maris C. e Gandour
Intima-media thickness of the common carotid artery was recommended as a useful parameter to assess the presence of coronary artery disease in a recent publication of the American Heart Association ${ }^{1}$. Most of the articles cited as references ${ }^{2-8}$, however, are prognostic studies. They refer to the capacity of a thicker intima-media layer of the (common and internal) carotid artery to predict the occurrence of coronary events, such as infarction or cardiac death, in a mean period of 2-4 years. Only the study by Leary et $\mathrm{al}^{2}$, assessing the intimal and media layers of elderly patients, reported a positive association between a thicker intima-media layer of the common carotid artery and the presence of coronary artery disease. In the medical literature, several studies ${ }^{9-12}$ about the association of the intimamedia layer and the presence of coronary artery disease use not only the common carotid artery to measure the intimamedia layer, but also the carotid bulb and the internal carotid artery. Adams et al ${ }^{12}$ specifically assessed the intimamedia layer of the common carotid artery and reported a weak association with the presence of coronary artery disease. On the other hand, Burke et al ${ }^{4}$ reported the occurrence of a positive association between a thicker intimamedia layer and the presence of coronary artery disease; the diagnosis of the presence or absence of the disease, however, was obtained only with the clinical history.

This study aimed at assessing the association of a thicker intima-media layer of the common carotid artery with the presence of coronary artery disease.

\section{Methods}

A prospective case-control study of prevalence was carried out and the sample assessed comprised 29 case patients, who had coronary artery disease and 29 healthy control patients. The inclusion criteria for the case patients were as follows: to be hospitalized at the Instituto de Cardiologia do Rio Grande do Sul from June to August 2001, to be 40 to 65 years of age, and to have coronary artery disease 
confirmed on cardiac catheterization or by myocardial infarction. The control group comprised consecutive asymptomatic patients with no previous history of cardiac pathology, aged 40 to 65 years, who underwent exercise testing with a normal result at the Clínica de Diagnósticos em Cardiologia (Labocordis) in August 2001. Patients with up to 1 risk factor (such as systemic arterial hypertension, smoking, or dyslipidemia) were accepted in the control group. The following patients were excluded from the study: those undergoing carotid artery surgery, those with diabetes, with peripheral vasculopathy, stroke, absence of an acoustic window, and lack of written informed consent.

The measurements of the intima-media thickness were performed in a noninvasive manner with an ultrasound device (HP 2500 or HP Multipoint 1800) and a 5-megahertz sectorial transducer with a 2-point discrimination capacity of $0.01 \mathrm{~mm}$. The value used as a measure of thickness of the intima-media layer was obtained after recording all the extensions of both common carotid arteries in VHS tape (off line). The measurements of the intima-media thickness were performed by an examiner who ignored whether the specimen belonged to the case or control group. The site chosen for measurement was the segment with the thickest intimamedia layer, independently whether it was the right or left carotid artery. Only the arterial wall further away from the transducer (contralateral to the transducer) was used for measurement. The intima-media thickness considered on ultrasound is the distance between the luminal face of the endothelium and the distal interface of the muscle layer ${ }^{13-15}$. In 10 randomly chosen patients, 2 new measurements were performed, 1 by the physician responsible for the measurements in the study and the other by an external examiner.

The following data were obtained either with an interview or through the analysis of the medical record: name, age (years), address, telephone, sex, smoking habit, presence of dyslipidemia, familial history, systemic arterial hypertension, hormone replacement, use of drugs with cardiovascular or lipid-lowering effects, previous cardiac surgery, previous cine coronary angiography, previous coronary angioplasty, and previous acute myocardial infarction. Measurements, such as weight $(\mathrm{kg})$ and height $(\mathrm{m})$, were taken at the time of the ultrasound examination.

Smoking was defined based on its active presence in the last 6 months; an ex-smoker was someone who quit the habit 6 months before; and a nonsmoker was someone who did not smoke in the last 15 years. Dyslipidemia was defined as the presence of LDL $\geq 160 \mathrm{mg} / \mathrm{dL}$ in the control group or $\geq 130 \mathrm{mg} / \mathrm{dL}$ in the group with coronary artery disease in a random measurement, or only the use of a lipid-lowering drug, or the presence of HDL $<35 \mathrm{mg} / \mathrm{dL}$. The presence of systemic arterial hypertension was considered when the use of antihypertensive drugs was reported, when a clinical history of hypertension existed, or when it was reported in the medical record. The familial history of early atherosclerosis was considered positive when cardiac death or infarction was reported in a male first-degree relative aged less than 45 years, or in a female first-degree relative aged less than 55 years. Hormone replacement was the use of estrogens after menopause. Myocardial infarction was considered when reported in the medical records with electrocardiographic and enzymatic documentation.

The statistical analysis used measures of summarization of the samples gathered, the $t$ test, and univariate analysis. A $P$ value $<0.05$ was considered significant.

The calculus of the size of the sample was 29 case patients and 29 control patients, based on a known mean referring to the intima-media thickness of $0.77 \mathrm{~mm}$, with standard deviation of $0.19 \mathrm{~mm}$, considering the clinically relevant difference of $0.15 \mathrm{~mm}^{16}$.

\section{Results}

Fifty-eight patients were assessed ( 29 case patients and 29 control patients), 32 (55.2\%) of whom were males [ 20 (69\%) males among the case patients and $12(41.4 \%)$ among the control patients]. Their mean age was $51+7.5$ years $[54+7$ years in the case patients and $48+7$ years in the control patients $(\mathrm{P}=0.07)]$. The mean height was $1.68+8.4 \mathrm{~m}$, and the mean weight was $73+11.54 \mathrm{~kg}$, and no statistically relevant difference existed between the case and control patients.

The frequency of the risk factors for coronary artery atherosclerosis is shown in table I. Dyslipidemia was present in $19(32.8 \%)$ patients ( 14 case patients and 5 control patients). Systemic arterial hypertension was identified in 26 $(44.8 \%)$ patients [20 (69\%) case patients and 6 (20\%) control patients]. Fourteen (24.1\%) case patients smoked. Familial history of early coronary artery disease was present in 17 (29.4\%) patients, 16 of whom were case patients. No patient was receiving hormone replacement. A significant difference was observed in regard to smoking and the presence of familial history of early coronary artery disease.

Three case patients underwent myocardial revascularization surgery, 7 (24\%) underwent coronary angioplasty, and $21(72 \%)$ underwent cine coronary angiography during the current hospitalization. Myocardial infarction was present in $18(62 \%)$ case patients. All case patients with systemic arterial hypertension used beta-blockers as antihypertensive drugs. Ten (34\%) case patients were using lipidlowering drugs, and no control patient used lipid-lowering or antihypertensive drugs.

All ultrasound examinations ( $100 \%$ ) provided images good enough to allow the measurement of the intima-media layer. The intraobserver and interobserver variations were, respectively, $0.05+0.02 \mathrm{~mm}$ and $0.07+0.04 \mathrm{~mm}$.

\begin{tabular}{|c|c|c|c|}
\hline \multicolumn{4}{|c|}{$\begin{array}{l}\text { Table I - Distribution of the risk factors for ischemic heart disease in } \\
\text { case and control patients }\end{array}$} \\
\hline & Total (\%) & Case $(\%)$ & Control (\%) \\
\hline Dyslipidemia & $19(32.8)$ & $14(48.3)$ & $5(17.2)$ \\
\hline Hypertension & $26(44.8)$ & $20(69)$ & $6(20)$ \\
\hline Smoking & $14(24.1)$ & $14(48.3)$ & 0 \\
\hline Familial history & $17(29.4)$ & $16(55.2)$ & $1(3.4)$ \\
\hline
\end{tabular}


The intima-media thickness of the common carotid arteries in case patients was significantly greater than that in control patients. The intima-media thickness was $0.81 \pm$ $0.25 \mathrm{~mm}(0.71+0.9 \mathrm{~mm})$ in case patients and $0.62 \pm 0.18 \mathrm{~mm}$ $(0.58-0.71 \mathrm{~mm})$ in control patients $(\mathrm{P}=0.001)$ (fig. 1$)$. The univariate analysis showed that smoking was the only relevant risk factor concerning the thicker intima-media layer.

\section{Discussion}

The intima-media thickness of the common carotid artery in the present study was greater in the group of patients with coronary artery disease. This finding is comparable to the results available in the specialized medical literature $^{2,8-12}$. The intima-media thickness of the common carotid artery found in the case patients was $0.81 \pm 0.25 \mathrm{~mm}(0.71$ $0.9 \mathrm{~mm}$ ), similar to that reported in the literature. Adams et $\mathrm{al}^{12}$ reported an intima-media thickness of $0.83 \pm 0.20 \mathrm{~mm}$ in patients with coronary artery disease. Blankenhorn et al ${ }^{17}$ reported an intima-media thickness of $0.65 \pm 0.11 \mathrm{~mm}$, and Lamont et al ${ }^{18}$ reported a mean of $0.79 \mathrm{~mm}(0.75 \pm 0.83 \mathrm{~mm})$.

The mean of the intima-media thickness of the common carotid artery in control patients was $0.62 \pm 0.18 \mathrm{~mm}$ $(0.58 \pm 0.71 \mathrm{~mm})$. That value approaches the results of studies in the literature. Pignoli et al ${ }^{13}$, comparing measurements obtained on ultrasonography with measurements obtained with anatomic specimen, reported the value of $0.53 \pm 0.05 \mathrm{~mm}$ in patients without coronary artery disease. Lamont et al ${ }^{18}$ reported a mean of $0.76 \mathrm{~mm}(0.74 \pm 0.78 \mathrm{~mm})$, and Schmidt-Truncksass et al ${ }^{19}$, analyzing 160 healthy and athletic males, found a mean of $0.73 \mathrm{~mm}$.

Despite the similarities with the results reported in the medical literature, some particularities of the present study should be emphasized. First of all, the technique used to measure the intima-media thickness, ie, the measurement of the thickest point of the intima-media layer, after screening the entire extension of the common carotid artery using only the contralateral wall is worthy of note. This technique is characterized as simple and rapid, but may not actually identify the thickest site. The acoustic window used in this study was exclusively the window of the posterior margin

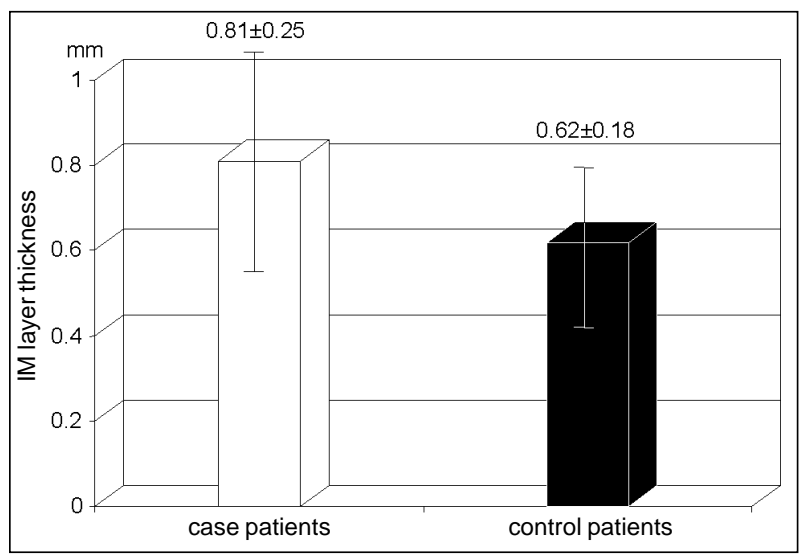

Fig.1 - Distribution of the intima-media layer thickness in case and control patients. of the sternocleidomastoid muscle, which generated measurements exclusively of the anteromedial wall of the common carotid artery. In the literature, a great variety of ways to measure the intima-media thickness may be found ${ }^{3,4,9,12,17,20}$. The 2 most frequently used techniques are cited below. The first refers to a mean of the measurements of the intima-media thickness of the common carotid artery, of the carotid bulb, and of the internal carotid artery taken in the proximal and distal walls, reported in the studies by Crouse et al ${ }^{9}$, Burke et $\mathrm{al}^{4}$, and Yamasaki et al ${ }^{20}$. The second technique was reported by Salonen et $\mathrm{al}^{3}$, Blankenhorn et al ${ }^{17}$, and Adams et al ${ }^{12}$, who chose to measure the intima-media thickness $10 \mathrm{~mm}$ distal from the common carotid bifurcation. Other techniques of measurement exist as follows: the one used by Hodis et al ${ }^{21}$, which consists in taking 80 measurements in a 1-cm segment in the thickest point of the carotid artery wall, and the method used by Nowak et al ${ }^{11}$, who measured the area of the intima-media layer situated $5-10 \mathrm{~mm}$ proximal to the bulb.

The method used in the present study is new and was chosen and applied because of the need to develop a rapid and simple technique that could maintain the association with coronary artery disease, making the procedure easier for assistance and research purposes.

The second particularity of this study refers to the criteria of sample selection. A sample with no clinical markers to identify patients suffering from coronary artery disease, even those with the disease like our case patients, was selected ${ }^{22}$. This was due to the fact that this study generated a population measurement of clinical and research interest, which may be used in the attempt to identify patients with coronary artery disease, even in the absence of the traditionally used clinical markers.

Still regarding the particularities of this study, at least 4 limitations should be considered: 1) the equipment to perform the examinations in the control group differs from that used in the case group; 2) the way of inferring the lack of coronary artery disease in the control group. The probability of an asymptomatic patient aged 40-65 years with a normal exercise test to have coronary artery disease is $1-3 \%^{23}$. It should be emphasized that the presence of the disease was not excluded and that, although ideal, cine coronary angiography was not performed in all patients due to ethical reasons; 3) the measurement of the risk factors was qualitative. Although the present study did not specifically aim at the risk factors, the univariate analysis suggested that smoking may have influenced the intima-media thickness, and the presence of the respective quantitative data could be useful for better understanding; and 4) neither the odds ratio, nor sensitivity, specificity, positive or negative predictive values were calculated, because the sample comprised $50 \%$ of patients with coronary artery disease, and, therefore, we would be calculating the diagnostic properties of a test in a sample with a very high pretest probability, which would generate inadequate results.

In conclusion, the common carotid artery intima-media thickness is greater in patients with coronary artery disease 
as compared with that in patients without the disease. Further studies should be carried out aiming at defining the diagnostic characteristics of the intima-media layer obtained with a simple measurement of the thickest segment of the common carotid artery in patients with no clinical evidence of coronary artery disease.

\section{References}

1. Smith SC, Greenland P, Grundy SM. Prevention Conference V. Beyond Secondary Prevention: identifying the high-risk patient for primary prevention. Executive Summary. Circulation 2000; 101: 111-6.

2. O'Leary DH, Polak JF, Manolio TA, et al. Cardiovascular health study collaborative research group: carotid artery intimal and media thickness as a risk factor for myocardial infarction and stroke in older adults. N Eng J Med 1999; 340: 14-22.

3. Salonen JT, Salonen R. Ultrasonographically assessed carotid morphology and the risk of coronary heart disease. Arterioscler Thromb 1991; 11: 1245-9.

4. Burke GL, Evans GW, Riley WA, et al. Arterial wall thickness is associated with prevalent cardiovascular disease in middle-aged adults. Stroke 1995; 26: 386-91

5. O'Leary DH, Polak JF, Kronmal RA, et al. Carotid-artery intima and media thickness as a risk factor for myocardial infarction and stroke in older adults. N Eng J Med 1999; 340: 14-22.

6. Hodis HN, Mack WJ, Labree L, etal. The role of carotid arterial intima-media thickness in predicting clinical coronary events. Ann Intern Med 1998; 128: 262-9.

7. Mannami T, Konisk M, Baba S, Nishi N, Terao A. Prevalence of asymptomatic carotid atherosclerotic lesions detected by high-resolution ultrasonography and its relation to cardiovascular risk factors in the general population of a Japanese city. Stroke 1997; 28: 518-25.

8. Bots ML, Hoes AW, Koudstool PJ, Hofman A, Grobbee DE. Common carotid intima-media thickness and risk of stroke and myocardial infarction. Circulation 1997;96: 1432-7.

9. Crouse JR, Craven TE, Hagaman AP, et al. Association of coronary disease with segment-specific intima-media thickening of the extracranial carotid artery. Circulation 1995; 92: 1141-7.

10. Craven TE, Ryu JE, Espeland MA, et al. Evaluation of the associations between carotid artery atherosclerosis and coronary artery stenosis. A case-control study. Circulation 1990; 82: 1230-42.

11. Nowak J, Nilsson T, Sylven C, Jogestrand T. Potential of carotid ultrasonography in the diagnosis of coronary artery disease. Stroke 1998; 29: 439-46.
12. Adams MR, Nakagomi A, Keech A, et al. Carotid intima-media thickness is only weakly correlated with the extent and severity of coronary artery disease. Circulation 1995; 92: 2127-34.

13. Pignoli P, Tremoli E, Poll A, et al. Intima plus media thickness of the arterial wall: a direct measurement with ultrasound imaging. Circulation 1986; 74 : 1399-06.

14. Junqueira LC, Carneiro J. Sistema circulatório. In. Junqueira LC. Histologia Básica. Rio de Janeiro: Guanabara, 1985.

15. Pimentel P. Estudo eco-color-doppler normal. In: Pimentel P, Ristow AV, Araujo WB. Eco-doppler da Artérias Carótidas e Vertebrais. Avaliação Diagnóstica e Correlação Angiográfica Cirúrgica. Rio de Janeiro: Revinter, 1993.

16. Ebrahim S. Use of B mode ultrasound of peripheral arteries as endpoint in clinical trials. Br Heart J 1994; 72: 501-3.

17. Blankenhorn DH, Selzer RH, Crawford DW, et al. Beneficial effects of colestipolniacin therapy on the common carotid artery. Circulation 1993; 88: 20-8.

18. Lamont D, Parkerl L, White M, et al. Risk of cardiovascular disease measured by carotid intima-media thickness at age 49-51: life course study. Br Med J 2000; $320 ; 273-8$.

19. Schmidt-Truncksass A, Grathwohe D, Schmid A, et al. Structural, functional, and hemodynamic changes of the common carotid artery with age in male subjects. Arterioscler Thromb Vasc Biol 1999; 19: 1091-7.

20. Yamasaki Y. Carotid intima-media thickness in Japanese type 2 diabetic subjects: predictors of progression and relationship with incident coronary heart disease. Diabetes Care 2000, 23; 1310-15.

21. Hodis HN, Mack WJ, Labree L, et al. Reduction in carotid arterial wall thickness using lovastatin and dietary therapy. Ann Intern Med 1996; 124: 548-56.

22. Gersh BJ, Braunwald E, Rutherford JD. Chronic coronary artery disease. In: Braunwald E. Textbook: Braunwald Heart Disease. A Textbook of Cardiovascular Medicine. Philadelphia: WB Saunders Company 1997.

23. Management of stable angina pectoris. Recommendations of the task force of the European Society of Cardiology. Eur Heart J 1997; 18: 394-413. 